\title{
Role of sociological methodology in determining criteria evaluating justice of punishment in criminal law
}

\author{
Viacheslav Voronin* \\ Kutafin Moscow State Law University (MSAL), Sadovaya-Kudrunskaya Str., 9, Moscow, 125993, Russian Federation
}

\begin{abstract}
In modern society, the role of concept of justice is increasing. Various decisions of state authorities are assessed from the standpoint of justice or injustice. However, the concept of justice has special significance in relation to state repression. Often society reacts to the use of state coercion against individuals and such situations are widely covered in the media, spark a great public outcry, sometimes lead to various kinds of conflicts between a part of society and officials. It is generally accepted that such situations of social tension are caused by the facts of excessive use of repression. However, we put forward the hypothesis that the perception of justice by society and concept of justice set out in the criminal law and perceived by the court are significantly different today, which causes systemic problems in the perception of justice. The solution to this problem is possible only with an integrated approach related to the study of the current criminal law and the potential of justice embedded in it, the perception of justice as a category in the activities of the court, as well as the idea of justice in public perception. The author had the following tasks: 1) to study the main approaches to justice in the modern system of social sciences, 2) set the parameters and forms of polling the population on the justice of punishment, 3) develop an anonymous questionnaire for judges in order to establish the factors, criteria and circumstances which they associate punishment tightening and mitigation with, 4) send the developed questionnaire to all courts of the constituent entities of the Russian Federation, 5) after the responses are received from the courts, carry out selective analysis of the sentences awarded by these courts and compare the circumstances noted in the sentences and affecting the punishment with those indicated by the judges in the questionnaires; 6) process all received sociological data and create the following scales: a) circumstances that should be regarded when assigning a just punishment based on public opinion; b) circumstances that judges regard when choosing a punishment in specific criminal cases. The article presents some results of the study conducted on the basis of a questionnaire survey of judges and the population, as well as a description of the survey methodology.
\end{abstract}

\section{Introduction}

Having considered the basic approaches to justice, we tried to disregard the social cycle formation that has developed in the system of Russian sciences and paid more attention to the existing approaches to the justice of punishment that prevail in Western socio-legal thought. The characteristic feature is not just understanding of this phenomenon within the framework of one, for example, legal science, but an integrated approach.

The following were considered as original theories of the justice of punishment: the political and legal theory of punishment and its justice based on the principles of fair play by the state (political scientist Richard Dagger, University of Arizona, USA), theories of consequentialism in punishment by John Leslie Mackey, Australia [1]; Theory of proportional retaliation by A. von Hirsch, UK, Cambridge [2]; The Theory of Retributivism by Michael Davis, USA, Illinois Institute of Technology [3]; The Theory of Censure in Punishment by Joel Feinberg, USA [4]. The above concepts can be considered basic and quite classical in Western philosophical and political-legal thought. In addition, we related to some of the more up-to-date approaches or their interpretations: "Retributarianism: a new individualization of punishment" by Adar DanzigRosenberg and Netanel Dagan [5], modern retributivism, a prominent representative of which is Goran DuusOtterström, Sweden [6].

One of the most significant and convincing theories of criminal punishment widespread in the West is retributivism being the theory of punitive treatment of a criminal. Retributivism today gets modern interpretations and arguments, thanks, in particular, to the works of the Swedish political scientist Göran DuusOtterström, who argues that even the traditional theory of punitive retribution in its modern interpretation assumes that the imposition of a just punishment is not isolated from public opinion [6].

If classical retributivism did not recognize the perpetrator's personality traits not directly related to the deed, for example, his positive post-crime behavior as a criterion of justice [7], then new trends began to appear,

\footnotetext{
Corresponding author: v.w.n@yandex.ru
} 
such as "retributiveism", which describes the tendency to expand the individualization of punitive influence by considering a number of different factors in order to increase the level of proportionality of the offense and punishment [5].

\section{Public opinion and justice of punishment}

Turning to the justice of punishment in public perception, it is worth noting that at present there is a critical question about what role public opinion (if any) should play in sentencing. Whether public opinion and censure should be the guiding force in how punitive policies and practices of punishment evolve or not. It is likely that today these questions are much more difficult to answer.

Over the past two decades, judges and politicians have been able to base their decisions on criminal penalties on their perceptions of what the public wants, although scholars generally regard this as a problem because the public is largely ill-informed about these matters. For example, public opinion can serve as a catalyst for unprincipled or overly punitive criminal policy decisions, such as new criminalizations or increased severity of punishment, for example, for sex offenses or drug trafficking offenses. However, is there any influence of public opinion on the sphere of justice and the activities of the court in imposing a just punishment?

Despite these concerns, some legal scholars agree that public opinion should have some weight although accompanied with the significant qualifications and disclaimers. Today there is a lot of uncertainty about the mentioned issues. For example, judges and politicians should regard opinion poll data on attitudes towards a possible punishment for a particular person in order to be able to elect a just measure. How do we decide what punishment is proportionate to the crime? What is the most objective way to determine proportionality? At what stage should public opinion be taken into account in criminal proceedings?

In particular, Jesper Ryberg believes that the dominant approach in criminal legal thought considers public opinion only in connection with the already formed theory of criminal punishment. The author argues that regardless of the existing theoretical approaches to punishment, nothing prevents us from developing a fundamentally new concept, on which both theorists of criminal law and sociologists being the researchers of public opinion can work together [8].

Within the framework of the existing global trends in the actualization of criminal law impact and its social conditioning, we conducted several sociological surveys of professional judges being directly involved in sentencing in accordance with the principle of justice, as well as a survey of the population about what the court should be guided by to award a just punishment.

\section{Parameters of judges' survey}

The main survey objective was to establish the factors, criteria and circumstances with which the judges associated the punishment toughening and mitigation, and, consequently, its justice. Traditional survey methods were combined with a written survey methodology.

The questionnaire consisted of 3 types of questions. The first type was an introductory part aimed to determine the status of the interviewed person. Specifically, it was proposed to indicate the region, name of the court and personal status, experience. If the respondent desired to receive generalized information about the research results, he/she could enter full name and contact information. This opportunity was used by 45 respondents $(5.2 \%$ of all respondents). Only 19 people left their contact e-mail, which shows the importance of the anonymous nature of the questionnaire and its undoubted advantage over the oral expert interviews of judges. This conclusion is based on the closed nature of the judicial corporation and the presence of restrictions on certain public statements, in particular, in connection with the criminal cases under consideration.

Therefore, it became necessary to augment the questionnaire with open-ended questions along with the traditional multiple choice questions. The second type of questions was multiple choice questions about the main characteristics of the justice of punishment and the punishment system. This type of questions was chosen due to the idea to provide respondents with the ability to select all the factors and supplement them with their own answers. The third type of questions was more related to an expert survey and interviewing and presupposed an independent formulation of an answer on a certain problematic topic. The answer to this type of questions showed, among other things, the level of the respondent's expert ability and his/her immersion in the problems associated with the issues of choosing a just punishment.

Also, questions with an open, detailed answer were supposed to significantly assist in determining the level of professional legal awareness of a judge, or his/her thinking in exclusively stereotyped categories from legal acts and the positions of the Supreme Court of the Russian Federation. One of the main tasks was to determine the extent to which judges and their legal consciousness are imbued with the requirement of justice when deciding on punishment. To fill out the questionnaire, the respondent had to have the following mandatory characteristics: having the status of a judge and experience in handling criminal cases. All materials of the questionnaire were sent with an official request addressed to the presidents of the courts with a request to assist in the conduct of the questionnaire among judges who are considering criminal cases.

In total, 865 judges considering criminal cases and representing 56 subjects of the federation took part in the survey. The representativeness of such a sample is 
difficult to assess, but if we are guided by official open data, then the Federal Law of December 2, 2019 No. 380-FL "On the federal budget for 2020 and for the planning period 2021 and 2022" established the number of judges of federal courts jurisdictions equal to 25,433 people. The following was approved: 171 courts of general jurisdiction, 16 military courts of appeal, 5,534 supreme courts of republics, regional courts, courts of federal cities, courts of autonomous regions, 17,991 district courts, 265 district (naval) military courts, 574 garrison military courts by order of the Judicial Department at the Supreme Court of the Russian Federation No. 276 "On the approval of the number of federal courts of general jurisdiction for 2020" dated December 5, 2019.

Thus, if we start from the planned number of all federal judges of 25,433 people, from which the judges of the military courts should be subtracted since they initially remained outside the survey, we get 24,553 judges. Since we interviewed 865 people, this is about $3.5 \%$ of all federal judges (excluding military court judges). This sample should be considered successful and quite representative, given the regional representation of $65 \%$.

It is worth paying attention to an important factor being the specialization of the interviewed judges specifically in the consideration of criminal cases. Thus, according to Art. 30 of the Code of Criminal Procedure of the Russian Federation, the composition of the court for the consideration of each criminal case is formed taking into account the workload and specialization of judges by using an automated information system. They note that it can be distinguished as the specialization of individual judges and their benches within the court (criminal, civil, administrative benches, judicial bench for the same or even more fractional categories of cases), i.e. functional specialization; and the specialization of individual courts and entire subsystems of courts (economic, administrative, constitutional courts, etc.), i.e. institutional specialization.

Thus, in the structure of the supreme courts of republics, regional courts, courts of cities with federal status, courts of the autonomous regions, there will be three benches: criminal, civil and administrative ones. For example, let us turn to the structure of the Moscow City Court: the number of judges considering civil cases is 86 , administrative cases -30 , and criminal cases -88 . The ratio of judges in criminal cases in relation to the total staff of the judiciary of the Moscow City Court (204 judges) is $43 \%$, which is less than half. In the Belgorod Regional Court, this ratio is even smaller: out of the total number of 80 judges, only 15 judges are engaged in the criminal bench, which is only $18.75 \%$, which is less than a quarter.

According to the data of the Judicial Department under the Supreme Court of the Russian Federation, in 2020 , the courts considered 21,420,054 civil cases, and if we add all administrative cases to this figure, we get only $30,470,795$ ones, while in the same period the courts considered only 748,853 criminal cases, which was about 40 times less than the combined civil and administrative cases. It is quite logical that the staffing and resource support for the consideration of criminal cases should be less. If at the level of regional and equivalent courts it is possible to track the number of judges with criminal specialization, then in relation to district courts it is much more difficult and benches, as a rule, are not distinguished.

Therefore, it seems impossible to determine the ratio of judges dealing with criminal and civil cases based on publicly available information. As well, at the level of district courts, the same judge can consider both criminal and simple civil cases in order to evenly distribute the total load. The conclusion about the representativeness of the sample should be made to regard the listed factors, on the basis of which it can be argued that a larger-scale questionnaire survey of judges on any issues has not been previously conducted.

The questionnaire was sent to all 85 constituent entities of the federation, to the court of the constituent entity, as well as to the courts of appeal and cassation courts of general jurisdiction located on the territory of each region. Finally, judges from 56 subjects of the federation took part in the survey. Therefore, the survey covered $65 \%$ of all regions, which can be considered successful. On average, 14 questionnaires were received from each region but the values differed by region since the maximum number of answers to the questionnaires were given by judges from the Stavropol Territory (95), St. Petersburg was in second place (58) and Moscow was in the third place ( 57).

Initially, questionnaires were not sent to Moscow courts due to their low activity in responding to inquiries. However, with the help of the judicial community, the Council of Judges of the Russian Federation, it was possible to question both the judges of the Moscow City Court and most district courts. Initially, we asked not more than 10 representatives from one court to participate in the survey and in most regions this requirement was met. However, some courts passed the questionnaire to lower courts, thus, it turned out that more questionnaires were filled out from one region. Additionally, the difference in the number of questionnaires by region was due to the presence of several courts: appeal or cassation courts of general jurisdiction, whose judges also took part in the questionnaire in the territory of one subject of the federation.

When defining the questions for judges, we asked a number of similar questions about punishment and we expected to receive similar answers to them. The idea was that we would be able to identify various factors affecting the justice of punishment, which judges take into account at different stages of sentencing: mitigating circumstances, data characterizing the perpetrator's identity, data enabling to use extraordinary means to mitigate repression: Para. 6, Art. 15 of the Criminal Code, specifically, changing the category of crime and Art. 64 of the Criminal Code - sentencing in the presence of exceptional circumstances. We avoided the third scale of circumstances which the courts referred to in the verdict since it was difficult to conduct a representative sample of sentences corresponding to the scale of the survey of judges. 
Therefore, we took into account the analysis of sentences and its results to verify the circumstances indicated by the judges in the questionnaire. Since these circumstances significantly coincided, it was difficult to trace their repeatability and regularity of consideration in different sentences.

\section{Results of judges' survey}

Let us present some results that follow from the judges' survey $[9,10]$. The first questions aimed to determine the expert level of judges' perception of what place justice occupies in criminal law. When answering question No. 1 "The concepts of the term "justice" in the generally consumer sense and in the sense presented in the criminal law: A) coincide, B) do not coincide, C) intersect, D) not comparable", the majority of judges $(59.6 \%)$ answered that these terms intersect. Therefore, the judges do not see equality between what the majority of the population understands by the term "justice" and what is understood by it in the criminal law. However, the intersection means that there are some similarities, which is logical. It remains unclear what is broader: the commonly used meaning of justice or its criminal law refraction.

A fairly large number of respondents (27.9\%) spoke in favor of the coincidence of these categories; therefore, they believe that the criminal law fully meets universal human ideas about justice and contains all its necessary criteria. $10.4 \%$ of respondents said that these meanings of justice did not coincide, which illustrates the widespread opinion about the excessive use of the term "justice" in the criminal law since the Criminal Code deprives it of that universal moral and ethical meaning that we usually put into this term and is limited only by separate legal criteria that an ordinary person does not think of. 2.9\% of respondents said that it was impossible to compare these personifications of justice. Answer to question No. 2 "Fairness of punishment in the criminal code is: A) the purpose of punishment, B) the criminal law principle; C) a necessary sign of punishment; D) everything the above; E) none of the above" assumed the possibility of multiple choice, and also included an option in which the respondent chose all of the above options.

The purpose of the question was to determine the level of understanding of how the criminal law used the term "justice". If we proceed from the theoretically correct interpretation, then the correct option is B) justice is a criminal law principle given in Art. 6 of the Criminal Code. This answer was chosen by $36.6 \%$ of the respondents. At the same time, little more respondents $(40.9 \%)$ agreed that justice was both a principle of criminal law, and the purpose of punishment and a necessary sign of punishment. There are grounds to consider justice as one of the goals of punishment, as indicated by $14.8 \%$ of respondents.

However, the Criminal Code interprets the restoration of social justice as the goal of punishment, which is interconnected with justice itself but represents its broader aspect. $21.4 \%$ of the respondents considered justice as a necessary sign of punishment. It seems that such a position is based on the requirement of Art. 60 of the Criminal Code on the need to impose a just punishment meaning that the punishment should be fair. Additionally, $0.7 \%$ of the respondents considered that none of the above had anything to do with justice. One of the questions asked was as follows: "Part 1 of Art. 60 of the Criminal Code says that the punishment appointed by the court should be fair.

What factors and circumstances make the assigned punishment fair?" This question is fundamental in the methodology of our research since it can be used as a base to build a scale of factors with the help of which the court justifies the justice of the punishment. It became predictable that the overwhelming majority of respondents chose the formulations which the criminal law itself in one way or another connects with the appointment of a just punishment, these are as follows: the nature and level of public danger of the act (91.3\%); the identity of the perpetrator $(84.3 \%)$; mitigating and aggravating circumstances $(75.2 \%)$.

Many chose other circumstances provided for in the Criminal Code: the effect of punishment on the correction of a convict (71.9\%), as well as the effect of punishment on the living conditions of the convict's family $(62.4 \%)$, the nature and degree of actual participation of a person in committing a crime with complicity $(58.7 \%)$ and a slightly smaller number noted the circumstances due to which the crime was not consummated $(34.1 \%)$. It is interesting how the judges reacted to factors that were not required to be taken into account directly in the law; among this most popular answer was the post-criminal behavior of a person $(43.2 \%)$, which is separately indicated as a mitigating circumstance (paragraphs " $i$ ", " $k$ " part 1 Art.61 of the Criminal Code).

However, independently it can act as a negative characteristic of the personality of the perpetrator and influence the punishment aggravation. The next factor chosen by $36.1 \%$ of respondents was the plea bargain (this factor can be attributed to a type of post-criminal behavior), and also courts often take it into account in sentences as a circumstance characterizing a person or as a mitigating circumstance on the basis of Part 2 of Art. 61 of the Criminal Code. The role in the commission of the crime was chosen by $41 \%$ of the respondents. The victim's opinion was chosen by $19.8 \%$, and the convicted person's opinion - only by $6.3 \%$ of the respondents.

Taking into account the opinion of the victim is ambiguously perceived in science and interpreted in practice. If the victim asks not to punish the perpetrator strictly, the court can take this into account even as a mitigating circumstance, but based on the requirements of the law, the victim's opinion cannot influence the punishment aggravation. The option "attitude of the defense and prosecution parties" was chosen by 5.9\% and the public reaction to the imposed punishment - by $5 \%$ of the respondents. Other factors were indicated by $4.8 \%$ of the respondents, among them the majority noted that everything indicated in the list of answer options had to be taken into account. 


\section{Parameters of the population survey}

The parameters of the population survey were determined, first of all, on the basis of the funding that was included in the estimate for attracting the services of a third-party organization since it was not possible to conduct it entirely on our own. The purpose of the survey was to study the opinion of Russians about the justice of punishment in the public mind, in the criminal law and at the discretion of the court.

Objectives of the survey: to determine what factors and circumstances should be taken into account by the court to consider the punishment imposed on a person to be just; determine which of the types of punishments introduced in the criminal code to a greater extent (in most cases) contribute to the implementation of the principle of justice; determine what traits contributing to positive characteristic of the offender's personality the court should pay attention to when passing a sentence; determine what traits contributing to negative characteristic of the offender's personality the court should pay attention to when passing a sentence; determine what kind of reaction is most often caused by the information disseminated by the media about the imposed punishment in certain resonant criminal cases; assess the fairness of sentences on the resonant criminal cases indicated in the questionnaire.

The objects of the survey were 300 residents of Moscow with various socio-demographic characteristics. The questionnaire was developed independently with regards to the entire purpose of our research, and it included 12 questions, which can be classified by form and content: multiple choice questions about the factors of justice in sentencing; open-ended questions about personality factors, single-answer questions that measure public response to punishment in specific criminal cases, and questions about the personality of respondents.

To answer the question about the factors and circumstances that the court must take into account so that the punishment imposed on a person could be considered fair, respondents from the list were asked to select everything they suppose should be considered in this issue.

The majority of the respondents selected the following factors: two thirds $(74 \%)$ pointed to the social danger of the deed as the main factor; half of the respondents indicated a confession (53\%); mitigating and aggravating circumstances $(50.7 \%)$; the perpetrator's good moral character (49\%). The rest of the factors were selected in the following sequence: role in the commission of the crime $-42.7 \%$; voluntary surrender $39.3 \%$; remediation $-33 \%$; the position of the defense and prosecution parties on punishment - 27.3\%; the victim's opinion about the punishment $-27 \%$; the effect of punishment on the correction of a convicted person $24.3 \%$; circumstances due to which the crime was not consummated - 20\%; the impact of punishment on the living conditions of the convict's family $-18.7 \%$; the reaction of society to the imposed punishment $-16.3 \%$; the convict's opinion about the punishment $-14 \%$.

\section{Conclusion}

Having compared the answers to this question, the following conclusions were made: the most popular answer implying that the social danger of the deed should be taken into account coincided with the polling of the population and judges. Additionally, when surveying judges and the population, the following factors were at the top of the scale: the identity of the perpetrator, mitigating and aggravating circumstances. It is important to note that there was not only a coincidence of opinions of two different categories of respondents: professional and general groups, but they also precisely those factors with which the criminal law connected the appointment of a just punishment listed in Part 3 of Art. 60 of the Criminal Code were chosen. This result was expected in the survey of judges, however, the population surprisingly understood the special legal terminology.

The study was supported by a grant from the Russian Science Foundation (project No. 20-78-00128)

\section{References}

1. J.L. Mackie, Persons and Values (Clarendon Press, Oxford, 1985)

2. A. Von Hirsch, Past or future crimes: Deservedness and dangerousness in the sentencing of criminals (Rutgers University Press, New Brunswick, 1985) 220 p.

3. M. Davis, Criminal desert and unfair advantage: What's the connection? Law and Philosophy, 12(2), 133-156 (1993)

4. J. Feinberg, Doing \& Deserving: Essays in the Theory of Responsibility (Princeton University Press, 1970)

5. H. Dancig-Rosenberg, N. Dagan, Retributarianism: A New Individualization of Punishment, Criminal Law and Philosophy, 13 (2019). DOI: 10.1007/s11572-018-9460-2.

6. G. Duus-Otterström, Retributivism and Public Opinion: On the Context Sensitivity of Desert, Criminal Law and Philosophy, 12(1), 125-142 (2018)

7. H. Maslen, Remorse, Penal Theory and Sentencing (Hart Publishing, 2015)

8. J. Ryberg, Penal Theory, Moral Intuitions, and Public Opinion, in: J. Ryberg, J. Roberts (eds.), Popular punishment: on the normative significance of public opinion (Oxford University Press, New York, 2014)

9. V. Voronin, Justice of Punishment as Social Compromise, Advances in Social Science, Education and Humanities Research, 420, 62-66 (2020).

10. V. Voronin, Justice In Russian Criminal Law, European Proceedings of Social and Behavioural Sciences, 108, 1482-1489 (2021). 